020

\section{EFFICACY OF A 2 MIN VERSUS A FULL 6 MIN PRACTICE WALK BEFORE A 6 MIN WALK TEST IN HEART FAILURE PATIENTS}

R Leslie, ${ }^{1} \mathrm{~K}$ George, ${ }^{2} \mathrm{~J}$ P Buckley ${ }^{1}$ Royal Wolverhampton NHS Trust; ${ }^{2}$ Liverpool John Moore's University; ${ }^{3}$ University of Chester

doi:10.1136/heartjnl-2013-304019.20

Objectives The 6 min walk test ( $6 \mathrm{MWT}$ ) is a useful measure of functional capacity for people with moderate to severe cardiorespiratory impairment (eg, chronic heart failure; $\mathrm{CHF}$ ). A practice $6 \mathrm{MWT}$ test is recommended in both clinical practice and research to increase the reliability of the test by aiming to filter out influences of familiarisation, pacing and motivation on final outcome tests. The effects of fatigue from a full $6 \mathrm{~min}$ practice test are also of practical concern in influencing $6 \mathrm{MWT}$ results. We therefore aimed to assess the efficacy of a 2 min versus a 6 min practice test on pacing and possible fatigue during a subsequent $6 \mathrm{MWT}$.

Methods Twenty patients diagnosed with CHF (55\% following coronary heart disease) were recruited. All patients were stable on optimal medical therapy for at least 4 weeks; all had exertional dyspnoea, fatigue or both and were classified according to New York Heart Association (NYHA) functional class II to III. Patients were allocated into two groups. Group $1(\mathrm{n}=10 ; 9$ male) performed a 2 min self-paced practice walk test (Grp1-2 min), +20 min rest, followed by a 6 MWT. Group $2(n=10 ; 7$ male $)$ performed a full $6 \mathrm{~min}$ practice test (Grp2-6 $\mathrm{min})+20 \mathrm{~min}$ rest, followed by a $6 \mathrm{MWT}$. Heart rate (HR) and ratings of perceived exertion (RPE) were monitored throughout all tests. A two factor (group by trial) repeated measures ANOVA was used to assess differences in HR and RPE (in the first $2 \mathrm{~min}$ ) and walking pace $\left(\mathrm{m} \mathrm{min}^{-1}\right)$ throughout all tests. Effects of pacing or fatigue on walking pace were further assessed between practice and follow-up 6 MWT using a bias $\pm 95 \%$ limits of agreement (LoA) analysis.

Results Mean (SD) walking distances and paces are summarised in table 1. Walking pace (table 1) was not different $(p>0.12)$ in either group between the practice and $6 \mathrm{MWT}$. HR and RPE were not different between or within groups $(p>0.37)$. Although walking paces were different between groups $(p=0.03)$, the group mean HR ( $82 \% H R$ max vs $80 \% H R m a x)$ and RPE (11.5 vs 11.2 ) showed there were no differences in relative exercise intensity between Grp1 and Grp2, respectively.

Discussion and conclusions Prior to performing a standard $6 \mathrm{MWT}$, whether the CHF patients performed a 2 min or a full $6 \mathrm{~min}$

Table 1

\begin{tabular}{|c|c|c|c|c|c|}
\hline Group & $\begin{array}{l}\text { Practice } \\
\text { distance } \\
\text { walked (m) }\end{array}$ & $\begin{array}{l}6 \text { MWT } \\
\text { distance } \\
\text { (m) }\end{array}$ & $\begin{array}{l}\text { Practice test } \\
\text { walk pace } \\
\left(\mathrm{m} \mathrm{min}^{-1}\right)\end{array}$ & $\begin{array}{l}6 \mathrm{MWT} \text { walk } \\
\text { pace } \\
\left(\mathrm{m} \mathrm{min}^{-1}\right)\end{array}$ & $\begin{array}{l}95 \% \text { LoA } \\
\text { practice vs } \\
6 \text { MWT } \\
\text { pace }\end{array}$ \\
\hline $\begin{array}{l}1: 2 \mathrm{~min} \\
\text { practice }\end{array}$ & $115(27.7)$ & $329(95.7)$ & 57.5 (13.8) & $54.9(15.9)$ & 12.1 \\
\hline $\begin{array}{l}2: \text { Full } \\
6 \text { min } \\
\text { practice }\end{array}$ & 404 (93.7) & $424(81.4)$ & ${ }^{*} 67.3(15.6)$ & ${ }^{*} 70.7(13.6)$ & 12.1 \\
\hline
\end{tabular}

practice test, the similar $95 \%$ LoA in walking pace between practice and $6 \mathrm{MWT}$ showed equal amounts of variability of pace. Although the full 6 min practice showed no sign of causing fatigue, this data has demonstrated preliminary evidence that a 2 min practice test is both time-saving and as effective in influencing pacing as a 6 min practice walk for CHF patients being assessed by a 6 MWT. Further data collection and analysis of the effects of a $2 \mathrm{~min}$ versus $6 \mathrm{~min}$ practice test on longer-term reliability of the $6 \mathrm{MWT}$ is still required. 